\title{
The Effects of Parental Labor Migration on Children's Mental Health in Rural China
}

\author{
Hechao Jiang ${ }^{1}$ (D) Taixiang Duan $^{2} \cdot$ Fang Wang $^{3}$
}

Accepted: 9 September 2021 /Published online: 14 September 2021

(c) The Author(s) 2021, corrected publication 2021

\begin{abstract}
Utilizing data from the China Education Panel Survey, we investigated the effects of parental migration and its duration on children's mental health in rural China. We obtained a sample of 3830 rural children, comprising 2769 children who lived with both parents, 512 children whose one parent had migrated, and 549 children whose both parents had migrated. The results of multiple regression and propensity score matching showed that absence of both parents was negatively correlated to children's mental health, with the migration of one parent having little effect. The negative effects related to parental labor migration became more apparent when we considered the duration of parents' migration. Compared with children whose parents were not absent, children who had been left behind for less than one year and those who had been left behind for more than one year both displayed poorer mental health. These findings urge us to infer that family arrangements have an important influence on children's psychological health. The findings also showed girls' mental health more likely to be affected than that of boys, which implied a gender difference in the impacts of parental migration. Research and policy implications are discussed.
\end{abstract}

Keywords Propensity score matching $\cdot$ Rural China $\cdot$ Mental health

The migration of farmers to the cities in search of work in the last 40 years has become the largest internal migration in Chinese history. Due to the localized management of the education system, a considerable percentage of migrants leave their children behind in their hometown, which results in long-term separation of parents

Hechao Jiang

jhchao@swufe.edu.cn

1 Research Institute of Social Development, Southwestern University of Finance and Economics, Chengdu, No. 555, Liutai Road, Wenjiang District, 611130 Chengdu, People's Republic of China

2 Department of Sociology, Hohai University, Nanjing, People's Republic of China

3 Department of Sociology, Xi' an Jiaotong University, Xi'an, People's Republic of China 
from children. The Ministry of Civil Affairs of China (MOCA, 2018) reported that 6.97 million rural children were separated from their parents for six months or more in 2018. Parental migration for work may significantly increase the family income, but it can also have serious negative effects on children's academic achievement and quality of life (Leung \& Fung, 2021; Liang \& Chen, 2007; Zhao et al., 2015).

Mental health is a basic indicator of a person's quality of life. The effects of parents' absence on children's mental health have aroused the attention of scholars at home and abroad. Because family is a very important social institution that shapes the development of children (Leung \& Fung, 2021), labor migration leaves children living in nonintact families. Fung (2021) found that children growing up in intact families presented fewer depression and anxiety than those raised in non-intact families. But previous studies have provided mixed descriptions of the relationship between parental migration and children's mental health in China. Some scholars have reported that the mental health of left behind children is poorer than that of children from intact families (Fan et al., 2010; Wu et al., 2015), while others have revealed that labor migration was not correlated to children's psychological health (Ren \& Treiman, 2016; Xu \& Xie, 2015). The divergent findings of these studies are largely due to the different representativeness of the samples: for example, Xu and Xie (2015) used a nationally representative sample, while other scholars drew upon regional survey data (Zhang et al., 2014).

The present study used China Education Panel Survey (CEPS) data to evaluate the influence of parents' absence on children's mental health. We divided rural children into three groups: those who lived with both parents, those whose one parent had migrated, and those who lived with either parent. We adopted a counterfactual framework to evaluate the influence of parental labor migration on children's mental health. Three novel contributions are made by this study. First, based on a national sample, this study assesses the impacts of parents' absence on the mental health of rural children and also any gender differences in these effects, with the results showing that labor migration was negatively correlated to children's psychological health overall, and that being left behind has a much larger impact on the psychological health of girls than of boys.

Second, again based on a national sample, this study evaluates the influence of the duration of parents' absence on children's mental health and also any gender differences in this influence, with the results showing that children whose parents have been out of the home for less than one year have a greater likelihood of being affected by parental labor migration, and that the effects are greater on girls than on boys. Third, the study used propensity score matching to evaluate the influence of parents' absence on children's mental health in rural China, which is marked by massive internal migration (Toyota et al., 2007). The existing research has rarely considered the self-selection bias of parental migration and the associated endogeneity problems.

\section{Literature Review}

Research on parental migration and children's mental health can be placed within the social stress paradigm, which is a dominant sociological framework for the research of mental health that highlights both individual and structural sources of depressive 
disorders (Avison et al., 2009; Pearlin et al., 1981). According to the social stress paradigm, parental labor migration is an important stressor that can cause depressive symptoms in children left behind, but there is group heterogeneity in the ability of boys and girls to cope with stress, and family support is a vital moderating mechanism to reduce the negative impacts of stress on mental health (Aneshensel, 1992; Avison et al., 2009; Turner \& Lloyd, 1995). Because parental labor migration reduces children's levels of social support, it increases mental health risks under this framework. More generally, Researches have showed that parent child separation, especially for long periods, reduces the quality of caring for children (Lu et al., 2019) and increases emotional distress among the remaining caregivers (Guo et al., 2009). Nonetheless, parental mobility also increases financial support for children through remittances, which reduces the negative effects of parent-child separation. Studies have shown that remittances can help to meet children's financial needs (Hilderbrandt \& Mckenzie, 2005) and relieve the emotional burden of the remaining caregivers (Brown \& Poirine, 2005), meaning that receiving remittances may also provide some psychological benefits to children. Therefore, previous studies have provided mixed descriptions of the relationship between parents' absence and children's mental health.

It has been found that labor migration left the emotional needs of rural children unsatisfied (Ye \& Lu, 2011). Although some researchers have found that labor migration was not associated with children's happiness, the loneliness of left behind children is much higher than of children whose parents did not migrate (Liu et al., 2009). Zhan et al. (2014) found that both parents away for work was negatively correlated to secondary school students' self-esteem, and that the effects were larger in girls. Wu et al. (2015) found that parental labor migration not only directly affected children's likelihood of experiencing depression, but also had an indirect effect through loss of familial and communal social capital.

Other studies have showed no significant effects of parents' absence on children's mental health. Xu and Xie (2015) analyzed the causal effects between labor migration and the subjective well-being of rural children by applying a PSM procedure to data taken from China Family Panel Studies. Their results show no differences between children whose parents were not absent and left behind children in depression or positive self-perspective. Ren and Treiman (2016) analyzed the influence of parental migration on emotional well-being of rural children. They found that it was the village or neighborhood environment, not parental migration, that affected the levels of happiness or depression. Zhou et al. (2020a) found parental labor migration was not correlated to left behind children's well-being. Parental labor migration was also not related to depression or anxiety in children (Shen et al., 2015). Within the positive youth development model, Wen et al. (2015) showed that labor migration was only positively related to children's problem behavior.

Some international migration studies have reported negative influence of parental migration on children's mental health. Asis (2006) found that children of migrants in the Philippines were more angry, confused, and worried than their counterparts in families without migrating parents. Similarly, it has been found that children left behind in Thailand and Indonesia were at a greater risk of poor subjective well-being than children whose parents were not absent (Graham \& Jordan, 2011). Botezat and 
Pfeiffer (2014) found that parental migration was related to more serious mental health conditions in Romania. Their results show that children from abroad were depressed more often. Mazzucato et al. (2015) analyzed the subjective well-being of children in transnational households in African nations, and revealed that children from transnational households fared worse than children whose parents were not absent, but living conditions mediated the relationship in Ghana.

The findings regarding the effects of parent's migration status on children's mental health in international migration studies have been more consistent than those of studies of the same relationship in the Chinese context. There are four possible explanations for this inconsistency in studies of China. First, the influence of labor migration on children's mental health might vary greatly from region to region in China. The studies that have reported significant negative influence of labor migration on children have been based on surveys in western China ( $\mathrm{Su}$ et al., 2012; Zhan et al., 2014), where the negative influences should be more pronounced. In contrast, the studies that have not found significant negative effects have drawn upon nationally representative survey data. For instance, the data used by $\mathrm{Xu}$ and Xie (2015) were taken from China Family Panel Studies.

Second, it is difficult to determine causality in the relationship between parents' absence and children's mental health using conventional regression models. The few studies that have taken the causal inference approach have found no effects of parental migration. The results of Xu and Xie (2015), who used a PSM procedure for their analyses, show that left behind children did not differ from other rural children in depression or positive self-perspective. Similarly, Ren and Treiman (2016), using community fixed effects models, found no differences between left-behind children and children whose parents were not absent in happiness or depression.

Third, a variety of measures have been used for mental health in previous studies. Most researches have investigated the influence of parental migration on one or more particular dimension of children's mental health, such as happiness (Ren \& Treiman, 2016), loneliness (Su et al., 2012), depression (Wu et al., 2015; Xu \& Xie, 2015), self-esteem (Zhan et al., 2014), or anxiety (Shen et al., 2015).

Fourth, according to the social stress paradigm, previous researches may have drawn confounding conclusions by ignoring the continuing effects of stressors. Pearlin et al. (1981) found that ongoing difficulties in social role enactment are both a product of eventful change and a pathway through which events damage emotional well-being. Previous studies have also found that the duration of parents' absence can have a significant influence on the emotional well-being and academic achievement of rural children (Jordan \& Graham, 2012; Zhou et al., 2014). It was also found that the longer the parents' absence, the greater the risk of emotional problems for left behind children (Fan et al., 2010). Jordan and Graham (2012) distinguished the duration of paternal labor migration in four Asia countries, and found that the duration of parents' absence was related to the general well-being of children. Nonetheless, they also found that children who lived most of their lives in the households of migrant mothers experienced higher levels of generally happy.

The social stress paradigm also reminds us of the need to consider gender differences in the effects of stressors. Graham and Jordan (2011) found that boys have better psychological well-being than girls in the Philippines and Vietnam. 
It was also found that boys had significantly fewer depressive symptoms than girls in China (Lu et al., 2012). Zhan et al. (2014) have rigorously assessed the effect of parents' absence on children's self-esteem and found that girls whose father or both parents migrated had significantly lower self-esteem than boys in the same situation. Evidence for an association between parents' absence and children's academic achievement also varies by sex. Zhou et al. (2014) evaluated the influence of parents' absence on children's Chinese scores and math scores and found that left-behind boys had significantly worse scores in math and Chinese, but no such effect was found for girls. Liu et al. (2018) estimated the heterogenous effects of returning migrant parents on the academic achievement of rural children. Their outcomes show that in terms of school performance, girls benefitted more than boys from the return of migrant parents.

Therefore, we proposed the following three hypotheses when examining the effects of parental migration and its duration on children's mental health:

Hypothesis 1: Parental migration is negatively related to children's mental health.

Hypothesis 2: The duration of parents' absence is negatively correlated to children's mental health.

Hypothesis 3: The effects of parental migration and its duration on children's mental health is stronger for girls than for boys in rural China.

\section{Method}

\section{Data}

The data used in the present study were derived from the second wave of the CEPS. The CEPS is a large-scale, longitudinal survey that began by surveying two cohorts-Grades 7 and 9-in the 2013-2014 academic year. The followup survey was conducted of the Grade 7 students in the 2014-2015 academic year, with 9449 valid responses. For our research sample, we deleted the Grade 9 students, urban children, and migrant children, and arrived at a sample size of 3,830 .

Some of the variables used in the study were taken from the first wave of the CEPS, for two reasons. First, because gender and age were no longer collected in the second wave of the CEPS, we obtained the values for these variables from the first wave. Second, to explore the influence of the duration of parental absence on children's mental health, we needed to identify the current situation of child-parental separation based on each child's living arrangements and migration status in the 2013-2014 and 2014-2015 academic years. Thus, we obtained the living arrangements and migration status from the first wave of the CEPS. All other variables used in the study were taken from the second wave of the CEPS. 


\section{Dependent Variables}

The dependent variable in this study was a factor analysis score of five items measuring depressive symptoms. Children were required to answer how often they had felt each of the following in the last 7 days: "blue," "too depressed to focus on anything," "unhappy," "not enjoying life," and "sad, sorrowful." For each item, the children were required to answer the degree of each of these symptoms of psychological distress on the following scale: 5 (none of the time), 4 (seldom), 3 (some), 2 (most) and 1 (all of the time). Although the questions on the survey were written in somewhat different terms, they are reflective of the major components of the items contained in the Center for Epidemiologic Studies Depression scale (CES-D) (Radloff, 1977).

We conducted a factor analysis on these variables to generate a mental health factor. Regarding the reliability of the 5-item mental health scale, the Cronbach's value for the five items was 0.905 , manifesting relatively high internal consistency. Then we linearly transformed the resulting distribution to a range from 0 to 100 , with 100 reflecting the highest degree of mental health. Finally, we generated a mental health score for 3,830 students. The average mental health of rural students was 69.55 , of male students was 70.489, and of female students was 68.494 .

\section{Independent Variables}

The independent variables were the parental migration and the duration of parental migration. We divided rural children into three groups: children who lived with both parents, children whose both parents had migrated, and children whose one parent had migrated. The children who lived without parental migration were defined as children who resided in intact rural families. The children whose one parent absent were defined as children who lived with only one parent because one of them had migrated for work. The children whose both parents had migrated were defined as those who lived with neither of their parents because their mother and father had migrated for work. Table 1 shows the distribution of the three categories of rural children. In the 2013-2014 academic year, $68.35 \%$ of the children lived in an intact family, $16.58 \%$ of the children were those whose both parents had migrated, and $15.06 \%$ of the children were those whose one parent had migrated. In the 2014-2015 academic year, there was no significant shift in the proportion of children in the each of these three categories.

Table 1 Distribution of $7^{\text {th }}$ grade rural children by living arrangement status in 20132014 and 2014-2015

\begin{tabular}{lllllll}
\hline & \multicolumn{2}{l}{$2013-2014$} & & \multicolumn{2}{l}{$2014-2015$} \\
\cline { 2 - 3 } \cline { 6 - 7 } & $n$ & & & $n$ & $\%$ \\
\hline Parents are non-migrants & 2609 & 68.35 & & 2769 & 72.30 \\
Left-behind child, one parent & 575 & 15.06 & & 512 & 13.37 \\
Left-behind child, neither parent & 633 & 16.58 & & 549 & 14.33 \\
Total & 3817 & 100 & & 3830 & 100 \\
\hline
\end{tabular}


We further distinguished three categories of rural children based on how long their parent/s had been away for work: children whose parents were not absent, children whose parents had migrated for less than one year, and children whose parents had migrated for more than one year. The classification was based on the category to which the children belonged in each of the 2013-2014 and 2014-2015 academic years. If a child was living in an intact family in the first academic year and then became a left-behind child in the second wave, he or she was considered a child whose parents had been absent for less than one year; if a child was a left-behind child in both of the surveys, he was considered a child whose parents had been working away for more than one year. Other child was considered an intact family child.

\section{Control variables}

We also integrated several control variables that may be correlated to parents' migration status and our mental health measure. The children's socioeconomic circumstances, which could be expected to contribute positively to mental health, were characterized by the parents' years of schooling and the family's socioeconomic status. The demographic covariates were gender and age of the child, health status, Han or non-Han ethnicity and the number of siblings. We also controlled for the differences in children's mental health across regions. Table 2 provides descriptive statistics for the key covariates.

\section{Identification Strategy}

\section{Basic Specification}

To investigate whether parental labor migration was correlated to children's mental health, we specified our basic regression model as follows:

$$
M H=\alpha+\beta M_{i}+X_{i} \lambda+\varepsilon
$$

where $\mathrm{MH}$ represents the measure of mental health and $M_{i}$ is the living arrangement or the duration of the parental migration. The living arrangement had three possible values: intact family child, children whose both parents had migrated, and children whose one parent had migrated. The duration of the parental migration also had three possible values: intact family child, child left behind for less than one year, and child left behind for more than one year. $X_{i}$ is a set of control variables, comprising age, sex, health status, ethnicity, number of siblings, parents' years of schooling, family socioeconomic status, and home region.

However, the decision of a parent to migrate for work is unlikely to be random, and might be influenced by certain attributes of the children, parents, and family. Therefore, differences between the left behind children and intact family children might not be the outcomes of being left behind, but rather those covariates that determine who is left behind. Such as, family socioeconomic status might impact both the decision of parents' migration and also their children's mental health, through channels that are not related to the children being left behind. So, a regression analysis 
Table 2 Descriptive statistics for the main control variables

\begin{tabular}{|c|c|c|c|c|c|c|}
\hline & \multicolumn{2}{|c|}{ Full sample } & \multicolumn{2}{|l|}{ Male } & \multicolumn{2}{|c|}{ Female } \\
\hline & Mean & SD & Mean & $\mathrm{SD}$ & Mean & SD \\
\hline Age & 14.66 & 0.772 & 14.74 & 0.778 & 14.58 & 0.757 \\
\hline Siblings & 0.923 & 0.770 & 0.830 & 0.755 & 1.028 & 0.774 \\
\hline \multirow[t]{2}{*}{ Parents' years of schooling } & 9.517 & 2.230 & 9.524 & 2.285 & 9.510 & 2.167 \\
\hline & $n$ & $\%$ & $n$ & $\%$ & $n$ & $\%$ \\
\hline \multicolumn{7}{|l|}{ Gender } \\
\hline Male & 2027 & 52.92 & - & - & - & - \\
\hline Female & 1803 & 47.08 & - & - & - & - \\
\hline \multicolumn{7}{|l|}{ Ethnicity } \\
\hline Other ethnicity & 403 & 10.52 & 210 & 10.36 & 193 & 10.70 \\
\hline Han ethnicity & 3427 & 89.48 & 1817 & 89.64 & 1610 & 89.30 \\
\hline \multicolumn{7}{|l|}{ Health } \\
\hline Good health & 2707 & 70.68 & 1476 & 72.82 & 1231 & 68.28 \\
\hline Average health & 945 & 24.67 & 452 & 22.30 & 493 & 27.34 \\
\hline Poor health & 178 & 4.65 & 99 & 4.88 & 79 & 4.38 \\
\hline \multicolumn{7}{|l|}{ Family SES } \\
\hline Affluent family & 157 & 4.10 & 103 & 5.08 & 54 & 3.00 \\
\hline Average family & 2435 & 63.58 & 1243 & 61.32 & 1192 & 66.11 \\
\hline Poor family & 1238 & 32.32 & 681 & 33.60 & 557 & 30.89 \\
\hline \multicolumn{7}{|l|}{ Region } \\
\hline Eastern China & 1612 & 42.09 & 856 & 42.23 & 756 & 41.93 \\
\hline Central China & 1347 & 35.17 & 716 & 35.32 & 631 & 35.00 \\
\hline Western China & 871 & 22.74 & 455 & 22.45 & 416 & 23.07 \\
\hline Total & 3830 & 100 & 2027 & 100 & 1803 & 100 \\
\hline
\end{tabular}

that simply compares the psychological health of left-behind children with that of intact family children, such as the ordinary least squares (OLS) regression, could not provide unbiased evaluates of the influences of parents' absence on children's mental health.

\section{Propensity score matching}

Ideally, it would be possible to observe the differences in mental health of the same child when they have been left behind and again when they have not. Unfortunately, no child can be in both states at the same time. Propensity score matching is one of the foremost approaches to this problem to have been adopted by social scientists (Heckman et al., 1998; Rosenbaum \& Rubin, 1983). The main practice is not to match the characteristics of an individual, but to first estimate the probability that an individual (or family) would enter the treatment group or the control group based on the subject's characteristics, and then to match according to probability size. 
Commonly used PSM approaches are local linear regression matching, kernel matching, radius matching, and nearest neighbor matching. We used the kernel matching approach in this study. The concrete steps for PSM were as follows. First, a logit model was adopted to evaluate the propensity score of each child in the sample. A kernel matching algorithm was then used to compute the PSM estimator. In our study, there were four treatment subgroups: children whose both parents had migrated, children whose one parent migrated, left behind for less than one year, and left behind for more than one year. The variable D took the values of 0 or 1 to represent the control group and the treatment group. With $M H_{1}$ representing the mental health score of a child, the average treatment effect on the treatment group can be presented as:

$$
A T T=E\left(M H_{1 i} \mid D_{i}=1, P(X)\right)-E\left(M H_{0 i} \mid D_{i}=1, P(X)\right)
$$

We also conducted a balance test to inspect whether features of the treatment group and the control group were significantly different. The t-test results showed that the features of the control group and the treatment group were not significantly difference after matching. Also, the standardized \% bias of each variable was substantially reduced after matching. The left side of Fig. 1 shows the standardized percentage bias of each variable before and after matching for the children whose one parent migrated (treatment group) and the children who lived with both parents (control group). The right side of Fig. 1 shows the standardized $\%$ bias of each variable before and after matching for the children whose both parents migrated (treatment group) and the children who lived with both parents (control group). The standardized \% bias of each variable in other matched cases were similar to those presented in Fig. 1.
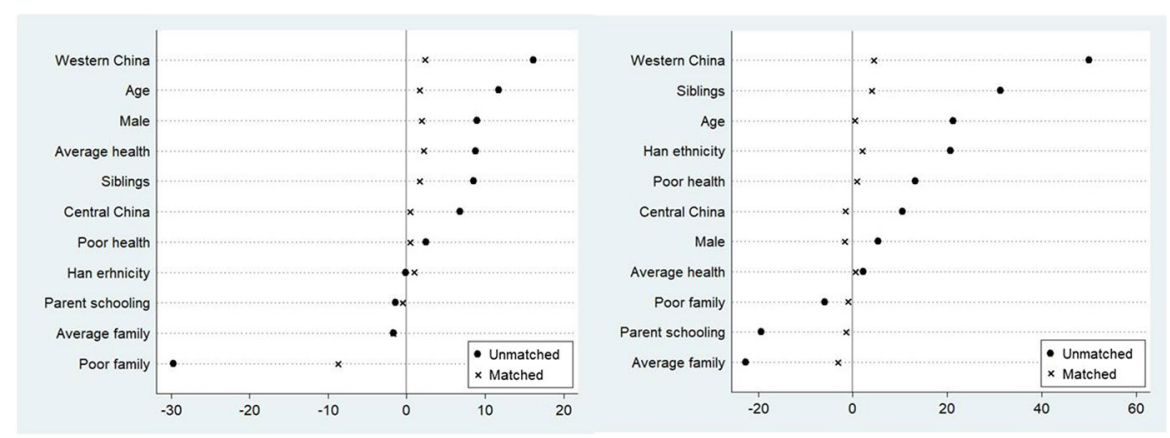

Fig. 1 Standardized \% bias across covariates. Note. Left: one parent away. Right: both parents away 
Table 3 Effects of parents' absence on children's mental health: results of an OLS regression

\begin{tabular}{|c|c|c|c|c|}
\hline & Full & Full & Male & Female \\
\hline & $(1)$ & (2) & (3) & (4) \\
\hline \multicolumn{5}{|l|}{ Parental migration status (Ref: Intact family) } \\
\hline \multirow[t]{2}{*}{ Left-behind child, one parent migrant } & $-2.687 *$ & -1.858 & -2.457 & -1.170 \\
\hline & $(1.050)$ & $(1.039)$ & $(1.445)$ & $(1.501)$ \\
\hline \multirow[t]{2}{*}{ Left-behind child, both parents migrants } & $-4.284 * * *$ & $-2.679 * *$ & -1.225 & $-4.530 * *$ \\
\hline & $(1.024)$ & $(1.034)$ & $(1.440)$ & $(1.496)$ \\
\hline \multirow[t]{2}{*}{ Male } & & $1.808^{*}$ & & \\
\hline & & $(0.710)$ & & \\
\hline \multirow[t]{2}{*}{ Age } & & -0.947 & -0.850 & -1.136 \\
\hline & & $(0.495)$ & $(0.697)$ & $(0.707)$ \\
\hline \multirow[t]{2}{*}{ Han ethnicity } & & -2.442 & -1.219 & -3.589 \\
\hline & & $(1.329)$ & $(1.910)$ & $(1.846)$ \\
\hline \multicolumn{5}{|l|}{ Health $(0=$ good $)$} \\
\hline \multirow[t]{2}{*}{ General } & & $-6.525 * * *$ & $-6.738 * * *$ & $-6.309 * * *$ \\
\hline & & $(0.819)$ & $(1.205)$ & $(1.112)$ \\
\hline \multirow[t]{2}{*}{ Poor } & & $-9.341 * * *$ & $-8.614 * * *$ & $-10.422 * * *$ \\
\hline & & $(1.694)$ & $(2.379)$ & $(2.415)$ \\
\hline \multirow[t]{2}{*}{ Siblings } & & -0.825 & -0.413 & -1.227 \\
\hline & & $(0.487)$ & $(0.705)$ & $(0.671)$ \\
\hline \multirow[t]{2}{*}{ Parents' years of schooling } & & -0.077 & -0.004 & -0.175 \\
\hline & & $(0.163)$ & $(0.227)$ & $(0.234)$ \\
\hline \multicolumn{5}{|l|}{ Family SES (Ref: Affluent family) } \\
\hline \multirow[t]{2}{*}{ Average family } & & $1.628^{*}$ & $2.171^{*}$ & 1.068 \\
\hline & & $(0.780)$ & $(1.107)$ & $(1.097)$ \\
\hline \multirow[t]{2}{*}{ Poor family } & & -0.046 & 1.477 & -2.502 \\
\hline & & $(1.867)$ & $(2.413)$ & $(3.015)$ \\
\hline \multicolumn{5}{|l|}{ Region (Ref: Eastern China) } \\
\hline \multirow[t]{2}{*}{ Central China } & & $-2.258 * *$ & -1.643 & $-2.941^{*}$ \\
\hline & & $(0.831)$ & $(1.192)$ & $(1.157)$ \\
\hline \multirow[t]{2}{*}{ Western China } & & $-2.329 *$ & $-3.121^{*}$ & -1.334 \\
\hline & & $(1.050)$ & $(1.503)$ & $(1.471)$ \\
\hline \multirow[t]{2}{*}{ Constant } & $70.520 * * *$ & $87.180 * * *$ & $85.833 * * *$ & $92.013 * * *$ \\
\hline & $(0.416)$ & (7.519) & (10.634) & $(10.752)$ \\
\hline$N$ & 3830 & 3830 & 2027 & 1803 \\
\hline$R^{2}$ & 0.006 & 0.045 & 0.038 & 0.054 \\
\hline
\end{tabular}

Standard errors are in parentheses

${ }^{*} p<0.05,{ }^{* *} p<0.01,{ }^{* * *} p<0.001$ 


\section{Results}

Table 3 displays the outcomes of an OLS analysis of parental migration on children's mental health. The result shows that in the model without control variables, parental migration was negatively correlated to children's psychological health (Model 1). In the model with control variables, parental migration was not correlated to children whose one parent had migrated $(\beta=-1.858, S E=1.039, p>0.05)$, but parental migration was still correlated to those whose both parents had migrated ( $\beta=-2.679, S E=1.034, p<0.01)$. Even so, compared with Model 1, the coefficient of parental labor migration is significantly reduced. Moreover, when we disaggregate the results by children's sex, they show that parental migration was only negatively related to the mental health of girls (Model 4), rather than the mental health of boys (Model 3).

Table 4 displays the results of PSM analysis. Panel A reveals the outcomes of a data analysis for children whose one parent had migrated and children who lived in intact families. Panel B reveals the outcomes of data analysis for children whose both parents had migrated and children who lived in intact families. The results in panel A show that the mental health of children whose one parent had migrated did not differ significantly from those whose parents were at home $(A T T=-2.034$, $S E=1.081, p>0.05)$. When we disaggregate the results by children's sex, there was still no significant difference for either males or females.

The results in panel $\mathrm{B}$ show that the children who lived with both parents and those whose both parents had migrated differed significantly in mental health between $(A T T=-2.581, S E=1.035, p<0.05)$. Moreover, when we disaggregated the results by children's sex, both parents migrating for work was only negatively related to the mental health of girls $(A T T=-3.905, S E=1.473, p<0.05)$ but not of boys. These results confirm the findings shown in Table 3, but, relative to the OLS regression results, also show a reduction in the effects for both the whole sample

Table 4 Average treatment effects of parents' absence on children's mental health

\begin{tabular}{|c|c|c|c|c|c|c|}
\hline & \multicolumn{2}{|c|}{ Treated } & \multicolumn{2}{|l|}{ Control } & \multirow[t]{2}{*}{ ATT } & \multirow[t]{2}{*}{ SE } \\
\hline & Mean & $n$ & Mean & $n$ & & \\
\hline \multicolumn{7}{|l|}{ Panel A } \\
\hline Full & 67.924 & 503 & 69.958 & 2707 & -2.034 & 1.081 \\
\hline Male & 67.771 & 283 & 70.339 & 1401 & -2.568 & 1.485 \\
\hline Female & 67.951 & 221 & 69.414 & 1314 & -1.463 & 1.561 \\
\hline \multicolumn{7}{|l|}{ Panel B } \\
\hline Full & 66.236 & 539 & 68.817 & 2694 & $-2.581^{*}$ & 1.035 \\
\hline Male & 68.680 & 293 & 69.985 & 1406 & -1.305 & 1.384 \\
\hline Female & 63.217 & 245 & 67.122 & 1300 & $-3.905^{*}$ & 1.473 \\
\hline
\end{tabular}

Type of matching algorithm: Kernel matching. ATT=average treatment effects. Panel A: Treated=children with one parent migrant, Control=intact family children; Panel B: Treated $=$ children with both parents migrants, Control = intact family children ${ }^{*} p<0.05$ 
and the female sub-sample. The effect was reduced from -2.679 (Table 3) to -2.581 (Table 4), and the effect on girls was reduced from-4.53 (Table 3) to -3.905 (Table 4). This indicates that a failure to eliminate self-selection bias will lead to overestimate the influences of parents' absence on children's mental health.

Table 5 displays the outcomes of an OLS analysis of the duration of parents' absence on children's mental health. The results of model 1 revealed a significant difference among the three groups of rural children. The results of model 2 showed that there was a significant difference between the mental health of children who had been left behind for less than one year and that of children whose parents were not absent, and between the mental health of children who had been left behind for more than one year and that of children whose parents were not absent. Compared with model 1 , however, the coefficient of parental labor migration was significantly reduced. Moreover, when we disaggregate the results by children's sex, they show that the duration of parental migration was negative related to girl's mental health, and had no influence on boys' mental health. As shown in Model 4, the duration of parents' migration was negatively correlated to children's mental health, but the difference in mental health scores between children whose parents had migrated for less than one year and those whose parents were not absent $(\beta=-4.015, S E=1.923$, $p<0.05)$ was much larger than that between children whose parents had been absent for more than one year and those whose parents were not absent $(\beta=-2.671$, $S E=1.298, p<0.05)$.

Table 6 displays the outcomes of a PSM analysis. Panel A shows the results of a data analysis of children left behind for less than one year and children whose parents were not absent. Panel B shows the results of a data analysis of children left behind for more than one year and children who lived in intact families. The results in panel A show a significant difference in mental health scores between children whose parents had migrated for less than one year and those whose parents were not absent. Overall, the mental health scores of children whose parents had been absent for less than one year were $3.77(S E=1.362, p<0.05)$ lower than those of children whose parents were not absent. When we disaggregate the results by children's sex, short periods of parental absence were negatively related to the mental health of girls. The results show that the mental health scores of girls who had been left behind for less than one year were $4.591(S E=2.215, p<0.05)$ lower than that of girls whose parents were not absent.

The results in panel $\mathrm{B}$ show a significant difference in mental health scores between children whose parents had migrated for more than one year and children whose parents were not absent. Overall, the influence of the duration of parental absence on children who had been left behind for more than one year were 1.974 $(S E=0.870, p<0.05)$ lower than those of children whose parents were not absent. When we disaggregate the results by children's sex, short periods of parental absence were still negatively related to girls' mental health. The results show that the mental health scores of girls who had been left behind for more than one year were $2.932(S E=1.324, p<0.05)$ lower than that of girls whose parents were not absent.

Moreover, the results in Table 6 show that parental absences of less than one year affected children's mental health more than absences of more than one year. 
Table 5 Effects of the duration of parents' absence on children's mental health: results of an OLS regression

\begin{tabular}{|c|c|c|c|c|}
\hline & Full & Full & Male & Female \\
\hline & (1) & $(2)$ & (3) & (4) \\
\hline \multicolumn{5}{|c|}{$\begin{array}{l}\text { Duration of parents' migration (Ref: } \\
\text { Not absent) }\end{array}$} \\
\hline \multirow[t]{2}{*}{ Less than one year } & $-3.880 * *$ & $-3.315^{*}$ & -2.705 & $-4.015^{*}$ \\
\hline & $(1.386)$ & $(1.365)$ & $(1.938)$ & $(1.923)$ \\
\hline \multirow[t]{2}{*}{ More than one year } & $-3.431 * * *$ & $-1.943^{*}$ & -1.425 & $-2.671 *$ \\
\hline & $(0.883)$ & $(0.892)$ & $(1.237)$ & $(1.298)$ \\
\hline \multirow[t]{2}{*}{ Male } & & $1.765^{*}$ & & \\
\hline & & $(0.708)$ & & \\
\hline \multirow[t]{2}{*}{ Age } & & -0.901 & -0.840 & -1.028 \\
\hline & & $(0.497)$ & $(0.700)$ & $(0.707)$ \\
\hline \multirow[t]{2}{*}{ Han ethnicity } & & -1.963 & -0.610 & -3.303 \\
\hline & & $(1.331)$ & $(1.917)$ & $(1.843)$ \\
\hline \multicolumn{5}{|l|}{ Health (Ref: Good health) } \\
\hline \multirow[t]{2}{*}{ Average health } & & $-6.746^{* * *}$ & $-7.045^{* * *}$ & $-6.534 * * *$ \\
\hline & & $(0.818)$ & $(1.204)$ & $(1.110)$ \\
\hline \multirow[t]{2}{*}{ Poor health } & & $-9.464 * * *$ & $-8.674 * * *$ & $-10.584 * * *$ \\
\hline & & $(1.686)$ & $(2.368)$ & $(2.406)$ \\
\hline \multirow[t]{2}{*}{ Siblings } & & $-1.000^{*}$ & -0.608 & $-1.414^{*}$ \\
\hline & & $(0.486)$ & $(0.704)$ & $(0.671)$ \\
\hline \multirow[t]{2}{*}{ Parents' years of schooling } & & -0.030 & 0.061 & -0.148 \\
\hline & & $(0.163)$ & $(0.228)$ & $(0.233)$ \\
\hline \multicolumn{5}{|c|}{ Family SES (Ref: Affluent family) } \\
\hline \multirow[t]{2}{*}{ Average family } & & 1.517 & 2.072 & 0.926 \\
\hline & & $(0.778)$ & $(1.108)$ & $(1.094)$ \\
\hline \multirow[t]{2}{*}{ Poor family } & & -0.192 & 1.307 & -2.825 \\
\hline & & $(1.860)$ & $(2.406)$ & $(3.002)$ \\
\hline \multicolumn{5}{|l|}{ Region (Ref: Eastern China) } \\
\hline \multirow[t]{2}{*}{ Central China } & & $-2.241 * *$ & -1.533 & $-3.071 * *$ \\
\hline & & $(0.831)$ & $(1.196)$ & $(1.154)$ \\
\hline \multirow[t]{2}{*}{ Western China } & & $-2.405^{*}$ & $-3.053 *$ & -1.670 \\
\hline & & $(1.048)$ & $(1.506)$ & $(1.462)$ \\
\hline \multirow[t]{2}{*}{ Constant } & $70.585^{* * *}$ & $86.392 * * *$ & $85.288 * * *$ & $90.707 * * *$ \\
\hline & $(0.415)$ & $(7.535)$ & $(10.679)$ & $(10.760)$ \\
\hline$N$ & 3830 & 3830 & 2027 & 1803 \\
\hline$R^{2}$ & 0.005 & 0.046 & 0.039 & 0.054 \\
\hline
\end{tabular}

Standard errors are in parentheses. ${ }^{*} p<0.05,{ }^{* *} p<0.01,{ }^{* * *} p<0.001$

Relative to the OLS regression results, these results show an increase in the effects for both the whole sample and the female sub-sample. For the whole sample, the effect of parental absence of less than one year on children's mental health increased 
Table 6 Average treatment effects of the duration of parents' absence on children's mental health

\begin{tabular}{|c|c|c|c|c|c|c|}
\hline & \multicolumn{2}{|l|}{ Treated } & \multicolumn{2}{|c|}{ Control } & \multirow[t]{2}{*}{ ATT } & \multirow[t]{2}{*}{ SE } \\
\hline & Mean & $n$ & Mean & $n$ & & \\
\hline \multicolumn{7}{|l|}{ Panel A: } \\
\hline Full & 66.704 & 268 & 70.474 & 2709 & $-3.770^{*}$ & 1.362 \\
\hline Male & 67.971 & 143 & 71.006 & 1405 & -3.035 & 2.067 \\
\hline Female & 65.174 & 124 & 69.766 & 1302 & $-4.591^{*}$ & 2.215 \\
\hline \multicolumn{7}{|l|}{ Panel B: } \\
\hline Full & 67.154 & 771 & 69.128 & 2677 & $-1.974^{*}$ & 0.870 \\
\hline Male & 68.476 & 429 & 70.031 & 1384 & -1.555 & 1.324 \\
\hline Female & 65.495 & 342 & 68.427 & 1285 & $-2.932^{*}$ & 1.324 \\
\hline
\end{tabular}

Type of matching algorithm: Kernel matching. ATT=average treatment effects. Panel A: Treated=parents absent for less than one year, Control $=$ parents not absent; Panel B: Treated $=$ parents absent for more than one year, Control $=$ parents not absent

${ }^{*} p<0.05$

from - 3.315 (Table 5) to -3.77 (Table 6), and the effect of parental absence of more than one year increased from -1.943 (Table 5) to - 1.974 (Table 6). For the subsample of girls, the effect of parental absence of less than one year on mental health increased from -4.015 (Table 5) to -4.591 (Table 6), and the effect of parental absence of more than one year increased from - 2.671 (Table 5) to - 2.932 (Table 6). This indicates that a failure to eliminate self-selection bias will tend to underestimate the effects of the duration of parents' absence on children's mental health.

We further tested for gender differences in the influence of parents' absence on children's mental health in Table 7. The results of model 1 display that boys' mental health was better than that of girls when both parents' absence. The results of model 2 display that the influence of the duration of parents' absence on children's mental health was moderated by gender, with boys experiencing better mental health than girls over the same period of parental absence. Those results imply that parents' absence and its duration influence the mental health of boys and girls differently.

\section{Discussion}

Utilizing data from the CEPS, we investigated the influence of parental migration and its duration on children's mental health in rural China. The results of multiple regression and propensity score matching showed that absence of both parents was negatively correlated to children's psychological health, with the migration of one parent having little effect. Moreover, the negative effects related to parental labor migration became more apparent when we considered the duration of parents' migration. Furthermore, the effects of parental migration of less than one year on children's mental health were much larger than the effects of parental migration of more than one year. This means that children whose parents had migrated for less than one year should receive additional emotional support. 
Table 7 Average treatment effects of parental migration on children's mental health

(1)

(2)

\begin{tabular}{|c|c|c|}
\hline \multicolumn{3}{|l|}{ Parents' migration status (Ref: Intact family) } \\
\hline Left-behind child, one parent migrant & $\begin{array}{l}-1.080 \\
(1.553)\end{array}$ & \\
\hline Left-behind child, both parents migrants & $\begin{array}{l}-4.436^{* *} \\
(1.517)\end{array}$ & \\
\hline Left-behind child with one parent migrant $\times$ Male & $\begin{array}{l}-1.367 \\
(2.079)\end{array}$ & \\
\hline Left-behind child with both parents migrants $\times$ Male & $\begin{array}{l}3.193^{*} \\
(1.725)\end{array}$ & \\
\hline \multicolumn{3}{|l|}{ Duration of parental migration (Ref: Not absent) } \\
\hline Less than one year & & $\begin{array}{l}-4.030^{*} \\
(1.997)\end{array}$ \\
\hline More than one year & & $\begin{array}{l}-2.590^{*} \\
(1.317)\end{array}$ \\
\hline Less than one year $\times$ Male & & $\begin{array}{l}1.345^{*} \\
(0.670)\end{array}$ \\
\hline More than one year $\times$ Male & & $\begin{array}{l}1.174^{*} \\
(0.489)\end{array}$ \\
\hline Male & $\begin{array}{l}1.547^{+} \\
(0.826)\end{array}$ & $\begin{array}{l}1.436^{+} \\
(0.825)\end{array}$ \\
\hline Age & $\begin{array}{l}-0.980^{*} \\
(0.496)\end{array}$ & $\begin{array}{l}-0.922^{+} \\
(0.497)\end{array}$ \\
\hline Han ethnicity & $\begin{array}{l}-2.428^{+} \\
(1.329)\end{array}$ & $\begin{array}{l}-1.971 \\
(1.331)\end{array}$ \\
\hline \multicolumn{3}{|l|}{ Health (Ref: Good health) } \\
\hline Average health & $\begin{array}{l}-6.488^{* * *} \\
(0.819)\end{array}$ & $\begin{array}{l}-6.759^{* * *} \\
(0.819)\end{array}$ \\
\hline Poor health & $\begin{array}{l}-9.349^{* * *} \\
(1.693)\end{array}$ & $\begin{array}{l}-9.462^{* * * *} \\
(1.686)\end{array}$ \\
\hline Siblings & $\begin{array}{l}-0.802^{+} \\
(0.487)\end{array}$ & $\begin{array}{l}-0.993^{*} \\
(0.487)\end{array}$ \\
\hline Parents' years of schooling & $\begin{array}{l}-0.080 \\
(0.163)\end{array}$ & $\begin{array}{l}-0.031 \\
(0.163)\end{array}$ \\
\hline \multicolumn{3}{|l|}{ Family SES (Ref: Affluent family) } \\
\hline Average family & $\begin{array}{l}1.639^{*} \\
(0.780)\end{array}$ & $\begin{array}{l}1.519^{+} \\
(0.779)\end{array}$ \\
\hline Poor family & $\begin{array}{l}0.028 \\
(1.867)\end{array}$ & $\begin{array}{l}-0.199 \\
(1.860)\end{array}$ \\
\hline \multicolumn{3}{|l|}{ Region (Ref: Eastern China) } \\
\hline Central China & $\begin{array}{l}-2.224^{* *} \\
(0.831)\end{array}$ & $\begin{array}{l}-2.234^{* *} \\
(0.831)\end{array}$ \\
\hline Western China & $-2.235^{*}$ & $-2.358^{*}$ \\
\hline
\end{tabular}


Table 7 (continued)

(1)

\begin{tabular}{lll}
\hline & $(1.052)$ & $(1.050)$ \\
Constant & $87.757^{* * *}$ & $86.872^{* * * *}$ \\
$N$ & $(7.544)$ & $(7.562)$ \\
$R^{2}$ & 3830 & 3830 \\
\hline
\end{tabular}

Standard errors are in parentheses

${ }^{+} p<0.1, * p<0.05, * * p<0.01, * * * p<0.001$

We also examined gender variations in the influence of parents' absence and its duration on children's psychological health. When we disaggregate the results by children's sex, we found that parental labor migration was only correlated to lower psychological health among girls. For the subsample of boys, parental labor migration was related to psychological health, while the mental health of left-behind boys was not statistically significant in relation to other rural boys. For the subsample of girls, parental migration status and the duration of their absence both had a negative impact on psychological health. The findings were in line with those of the full sample. The results of interaction effects showed that the influence of parental migration was moderated by gender, and that boys' mental health was better than girls' mental health under the same parental migration status or duration of parental migration.

Our finding that parental labor migration was negative related to the mental health of girls corresponds to findings from research conducted in the contexts of Hong Kong (Leung \& Shek, 2016) and Southeast Asia (Graham \& Jordan, 2011). There are many explanations for the gender difference. First, the extensive literature on family structures and migration indicates that girls tend to be influenced by early life stressors than boys (Zhou et al., 2014), because girls tend to be more sensitive to environmental changes. Second, the cultural practices of Chinese parents regarding the character of boys and girls also play a role. Chen and Liu (2012) showed that boys would expect to establish character traits such as independence and masculinity, while girls were expected to have character traits such as dependency and fulfilling relational obligations in their childhood. The different ways parents raise their daughters and sons may result in girls being more vulnerable and boys more resilience when confronted with family separation. Third, there is still a strong preference for boys in rural China, with parents often placing more emphasis on meeting the material and emotional needs of boys than of girls, which may also contribute to the poorer mental health of girls.

There are several practical implications of our findings. First, this study found that labor migration was negatively correlated to children's psychological health. It appears that parental companionship has a crucial influence on children's development, and family-supportive social policies are required to improve children's quality of life. For example, policies are needed to support family migration and enable migrant families to work and live together in destination cities. The current lack of family support policies has led cities to only accept rural laborers as workers, but 
not to give their children the opportunity to study. We argue that the main step in solving the problems faced by those children is the radical reform of basic public services in cities, such as labor protection, housing and education, so that migrant workers can settle in destination cities with their children. Without such policies, the negative effects of parents' absence on children left behind is likely to have serious consequences.

Second, the study found that mental health was significantly poorer in children who had been left behind for less than one year. This suggests that children who had been left behind for less than one year not only need additional emotional support, but also need to be protected from the negative effects of the circular migration of their parents as much as possible. Migrants tend to return to their hometowns during the busy farming season and the Spring Festival, but after a short reunion with their families, they soon return to the city to work (Hu et al., 2008). The circular migration of their parents may cause feelings of constant abandonment in left-behind children. One possible solution would be to develop the rural economy so that it can meet the needs of rural residents for non-agricultural work and allow rural children to live in intact families.

Third, the study found that the mental health of girls was more susceptible to parental migration. This provides vital clues for social workers to develop intervention strategies to assist children living in migrant families. One effective practical strategy may be to reinforce the communication between migrant workers and their children, to allow their children to feel the love of their parents. Teachers and classmates can also be encouraged to give provide help and companionship to leftbehind girls to offset the negative impact of parental migration. Furthermore, Shek and Liang (2018) found that parental sacrifice affected children's wellbeing through filial piety, which implied that children may experience psychological well-being in their interactions if parents explain their sacrifice to their children. This may also be another effective intervention.

Finally, the results also imply that we should promote the psychosocial competence of rural children. The PYD program has been shown in some Western countries to be a highly promising intervention for reducing depression in adolescents (Qi et al., 2020), and there are studies indicating that this intervention is also effective for Chinese adolescents (Shek \& Zhu, 2020; Zhou et al., 2020c; Zhu \& Shek, 2020). One possible solution would be to implement the PYD program in the school context where the students are allowed to engage in $10 \mathrm{~h}$ of training each year (Ma et al., 2011). Another possible solution would be to implement the PYD program in a community context, which would benefit more students in a district than would a program offered in a particular school, and could be implemented at flexible times (Ma et al., 2019). Regardless of the implementation details, under the current conditions it appears that operating the PYD program in rural China is the most feasible way to protect left-behind children from depression.

This study has some limitations. First, the depression symptoms were not measured with a standard instrument, for instance CES-D. Because the analysis drew upon existing survey data, the measurement of the children's mental health through depressive symptoms was operationalized using existing questions, which may have biased the results. Second, the present study only covered Grade 8 students and is 
therefore only reflective of the psychological health status of secondary school students in rural China; future research should explore the psychological health status of all ages in rural China. Third, although the social stress paradigm has pointed to social support as a vital mechanism in the influence of parental migration on children's mental health, the existing researches suggest that the influences of different types of social support are varied, and future studies need to examine in depth the role of various forms of social support.

Acknowledgements This research was supported by "the Youth Program of the National Social Science Fund of China" (Grant Number: 18CRK009), "the Chengdu Philosophy and Social Science Foundation Project" (Grant Number: 2019L35), "the Project of Philosophy and Social Science Research in Colleges and University in Jiangsu Province" (Grant Number: 2020SJA0101) and "the Jiangsu Philosophy and Social Science Foundation Project" (Grant Number: 20JYB010).

\section{Declarations}

Conflict of Interest The authors declare that they have no conflict of interest.

Open Access This article is licensed under a Creative Commons Attribution 4.0 International License, which permits use, sharing, adaptation, distribution and reproduction in any medium or format, as long as you give appropriate credit to the original author(s) and the source, provide a link to the Creative Commons licence, and indicate if changes were made. The images or other third party material in this article are included in the article's Creative Commons licence, unless indicated otherwise in a credit line to the material. If material is not included in the article's Creative Commons licence and your intended use is not permitted by statutory regulation or exceeds the permitted use, you will need to obtain permission directly from the copyright holder. To view a copy of this licence, visit http://creativecommons.org/licen ses/by/4.0/.

\section{References}

Aneshensel, C. S. (1992). Social stress: Theory and research. Annual Review of Sociology, 18, 15-38. https://doi.org/10.1146/annurev.so.18.080192.000311

Asis, M. M. (2006). Living with migration: Experiences of left-behind children in the Philippines. Asian Population Studies, 2(1), 45-67. https://doi.org/10.1080/17441730600700556

Avison, W. R., Anderson, C. S., Schieman, S., \& Wheaton, B. (Eds.). (2009). Advances in the conceptualization of the stress process: Essays in honor of Leonard I. Pearlin. Springer.

Botezat, A., \& Pfeiffer, F. (2014). The impact of parents migration on the wellbeing of children left behind: initial evidence from Romania. IZA Discussion Paper No. 8225. Institute for the Study of Labor, Bonn.

Brown, R. P., \& Poirine, B. (2005). A model of migrants' remittances with human capital investment and intrafamilial transfers. International Migration Review., 39, 407-438. https://doi.org/10.1111/j. 1747-7379.2005.tb00272.x

Chen, J. L., \& Liu, X. (2012). The mediating role of perceived parental warmth and parental punishment in the psychological well-being of children in rural China. Social Indicators Research, 107(3), 483-508. https://doi.org/10.1007/s11205-011-9859-9

Fan, F., Su, L., Gill, M. K., \& Birmaher, B. (2010). Emotional and behavioral problems of Chinese leftbehind children: A preliminary study. Social Psychiatry and Psychiatric Epidemiology, 45(6), 655664. https://doi.org/10.1007/s00127-009-0107-4

Fung, A.L.C. (2021). The significance of family structure in internalizing (anxious/depressed) and externalizing (aggressive/delinquent) problems among Chinese adolescents. Applied Research in Quality of Life. https://doi.org/10.1007/s11482-021-09923-9 
Graham, E., \& Jordan, L. P. (2011). Migrant parents and the psychological well-being of left-behind children in southeast Asia. Journal of Marriage and Family, 73(4), 763-787. https://doi.org/10.1111/j.17413737.2011.00844.x

Guo, M., Aranda, M. P., \& Silverstein, M. (2009). The impact of out-migration on the inter-generational support and psychological wellbeing of older adults in rural China. Ageing and Society, 29(07), 1085. https://doi.org/10.1017/S0144686X0900871X

Heckman, J., Ichimura, H., \& Todd, P. (1998). Matching as an econometric evaluation estimator. The Review of Economic Studies, 65(2), 261-294. https://doi.org/10.2307/2971733

Hilderbrandt, N., \& McKenzie, D. (2005). The effect of migration on child health in Mexico. Economia, 6, 257-289. https://doi.org/10.1353/eco.2006.0009

Hu, X., Cook, S., \& Salazar, M. A. (2008). Internal migration and health in China. The Lancet, 372(9651), 1717-1719. https://doi.org/10.1016/S0140-6736(08)61360-4

Jordan, L. P., \& Graham, E. (2012). Resilience and well-being among children of migrant parents in SouthEast Asia. Child Development, 83(5), 1672-1688. https://doi.org/10.1111/j.1467-8624.2012.01810.x

Leung, J.T.Y., Fung, A.L. (2021). Editorial: Special issue on quality of life among children and adolescents in chinese societies. Applied Research Quality Life. https://doi.org/10.1007/s11482-021-09915-9

Leung, J. T. Y., \& Shek, D. T. L. (2016). Parent-child discrepancies in perceived parental sacrifice and achievement motivation of Chinese adolescents experiencing economic disadvantage. Child Indicators Research, 9, 683-700. https://doi.org/10.1007/s12187-015-9332-4

Liang, Z., \& Chen, Y. P. (2007). The educational consequences of migration for children in China. Social Science Research, 36(1), 28-47. https://doi.org/10.1016/j.ssresearch.2005.09.003

Liu, Z., Li, X., \& Ge, X. (2009). Left too early: The effects of age at separation from parents on Chinese rural children's symptoms of anxiety and depression. American Journal of Public Health, 99(11), 2049. https://doi.org/10.2105/AJPH.2008.150474

Liu, Z., Yu, L., \& Zheng, X. (2018). No longer left-behind: The impact of return migrant parents on children's performance. China Economic Review, 49, 184-196. https://doi.org/10.1016/j.chieco.2017.06. 004

Lu, Y., Hu, P., \& Treiman, D. J. (2012). Migration and depressive symptoms in migrant-sending areas: Findings from the survey of internal migration and health in China. International Journal of Public Health, 57(4), 691-698. https://doi.org/10.1007/s00038-011-0314-0

Lu, Y., Yeung, J. W., Liu, J., \& Treiman, D. J. (2019). Migration and children's psychosocial development in China: When and why migration matters. Social Science Research, 77, 130-147. https://doi.org/10. 1016/j.ssresearch.2018.09.002

Ma, C. M. S., Shek, D. T. L., \& Chen, J. M. T. (2019). Changes in the participants in a community-based positive youth development program in Hong Kong: Objective outcome evaluation using a one-group pretest-posttest design. Applied Research in Quality of Life, 14(4), 961-979. https://doi.org/10.1007/ s11482-018-9632-1

Ma, H. K., Shek, D. T. L., \& Merrick, J. (2011). Project P.A.T.H.S. In Hong Kong: New curriculum in response to adolescent developmental issues. The Scientific World Journal, 11, 2424-2427. https://doi. org/10.1100/2011/961365

Mazzucato, V., Cebotari, V., Veale, A., White, A., \& Vivet, J. (2015). International parental migration and the psychological well-being of children in Ghana, Nigeria, and Angola. Social Science \& Medicine, 132(3), 215-224. https://doi.org/10.1016/j.socscimed.2014.10.058.

Ministry of Civil Affairs of China. (2018). Statistics of rural left-behind children in 2018. URL: http://www. mca.gov.cn/article/gk/tjtb/201809/20180900010882.shtml.

Pearlin, L. I., Lieberman, M. A., Menaghan, E. G., \& Mullan, J. T. (1981). The stress process. Journal of Health and Social Behavior, 22(4), 337-356.

Qi, S., Hua, F., Zhou, Z., \& Shek, D. T. L. (2020). Trends of positive youth development publications (1995-2020): A scientometric review. Applied Research in Quality of Life. https://doi.org/10.1007/ s11482-020-09878-3

Radloff, L. S. (1977). The CES-D Scale: A self-report depression scale for research in the general population. Applied Psychological Measurement, 1(3), 385-401. https://doi.org/10.1177/014662167700100306

Ren, Q., \& Treiman, D. J. (2016). The consequences of parental labor migration in China for children's emotional wellbeing. Social Science Research, 58(4), 46-67. https://doi.org/10.1016/j.ssresearch.2016.03. 003

Rosenbaum, P. R., \& Rubin, D. B. (1983). The central role of the propensity score in observational studies for causal effects. Biometrika, 70(1), 41-55. https://doi.org/10.1093/biomet/70.1.41 
Shen, M., Gao, J., Liang, Z., Wang, Y., Du, Y., \& Stallones, L. (2015). Parental migration patterns and risk of depression and anxiety disorder among rural children aged 10-18 years in China: A cross-sectional study. British Medical Journal Open, 5(12), 1-8. https://doi.org/10.1136/bmjopen-2015-007802

Shek, D. T. L., \& Liang, L. Y. (2018). Psychosocial factors influencing individual well-being in Chinese adolescents in Hong Kong: A six-year longitudinal study. Applied Research in Quality of Life, 13, 561-584. https://doi.org/10.1007/s11482-017-9545-4

Shek, D. T. L., \& Zhu, X. Q. (2020). Promotion of thriving among Hong Kong Chinese adolescents: Evidence from eight-wave data. Research on Social Work Practice, 30(8), 870-883. https://doi.org/10. $1177 / 1049731520947156$

Su, S., Li, X., Lin, D., Xu, X., \& Zhu, M. (2012). Psychological adjustment among left-behind children in rural China: The role of parental migration and parent-child communication. Child Care Health and Development, 39(2), 162-170. https://doi.org/10.1111/j.1365-2214.2012.01400.x

Toyota, M., Yeoh, B. S. A., \& Nguyen, L. (2007). Bringing the 'left behind' back into view in Asia: A framework for understanding the 'migration-left behind nexus.' Population, Space Place, 13, 157-161. https://doi.org/10.1002/psp.433

Turner, R. J., \& Lloyd, D. A. (1995). Lifetime traumas and mental health: The significance of cumulative adversity. Journal of Health \& Social Behavior, 36(4), 360-376. https://doi.org/10.2307/2137325

Wen, M., Su, S., Li, X., \& Lin, D. (2015). Positive youth development in rural China: The role of parental migration. Social Science \& Medicine, 132, 261-269. https://doi.org/10.1016/j.socscimed.2014.07.051

Wu, Q., Lu, D., \& Kang, M. (2015). Social capital and the mental health of children in rural China with different experiences of parental migration. Social Science \& Medicine, 132, 270-277. https://doi.org/10. 1016/j.socscimed.2014.10.050

Xu, H., \& Xie, Y. (2015). The causal effects of rural-to-urban migration on children's well-being in China. European Sociological Review, 31(4), 502-519. https://doi.org/10.1093/esr/jcv009

Ye, J., \& Lu, P. (2011). Differentiated childhoods: Impacts of rural labor migration on left-behind children in China. The Journal of Peasant Studies, 38(2), 355-377. https://doi.org/10.1080/03066150.2011.559012

Zhan, X., Li, S., Liu, C., \& Zhang, L. (2014). Effect of migration on children's self-esteem in rural China. China \& World Economy, 22(4), 83-101. https://doi.org/10.1111/j.1749-124X.2014.12076.x

Zhang, H., Behrman, J. R., Fan, C. S., Wei, X., \& Zhang, J. (2014). Does parental absence reduce cognitive achievements? evidence from rural China. Journal of Development Economics, 111, 181-195. https:// doi.org/10.1016/j.jdeveco.2014.09.004

Zhao, J., Liu, X., \& Wang, M. (2015). Parent-child cohesion, friend companionship and left-behind children's emotional adaptation in rural China. Child Abuse \& Neglect, 48, 190-199. https://doi.org/10. 1016/j.chiabu.2015.07.005

Zhou, M., Murphy, R., \& Tao, R. (2014). Effects of parents' migration on the education of children left behind in rural China. Population and Development Review, 40, 273-292. https://doi.org/10.1111/j. 1728-4457.2014.00673.x

Zhou, Q., Guo, S., \& Lu, H.J. (2020a). Well-being and health of children in Rural China: The roles of parental absence, economic status, and neighborhood environment. Applied Research in Quality of Life. https://doi.org/10.1007/s11482-020-09859-6

Zhou, Z., Shek, D. T. L., Zhu, X., \& Dou, D. (2020b). Positive youth development and adolescent depression: A longitudinal study based on Mainland Chinese high school students. International Journal of Environment Research and Public Health, 17, 4457. https://doi.org/10.3390/ijerph17124457

Zhou, Z., Shek, D. T. L., \& Zhu, X. (2020c). The importance of positive youth development attributes to life satisfaction and hopelessness in Mainland Chinese adolescents. Frontiers in Psychology, 11, 553313. https://doi.org/10.3389/fpsyg.2020.553313

Zhu, X., \& Shek, D. T. L. (2020). Impact of a positive youth development program on junior high school students in mainland China: A pioneer study. Children and Youth Services Review, 114, 105022. https:// doi.org/10.1016/j.childyouth.2020.105022

Publisher's Note Springer Nature remains neutral with regard to jurisdictional claims in published maps and institutional affiliations. 